This document is the accepted manuscript version of the following article:

Billeter, E., McGlamery, D., Aebli, M., Piveteau, L., Kovalenko, M. V., \& Stadie, N. P. (2018). Bulk phosphorus-doped graphitic carbon. Chemistry of Materials, 30(14), 4580-4589. https:// doi .org/10.1021/acs . chemmater. 8 b00944

\title{
Bulk Phosphorus-Doped Graphitic Carbon
}

\author{
Emanuel Billeter ${ }^{\# \dagger}$, Devin McGlamery ${ }^{\#}$, Marcel Aebli ${ }^{\dagger}$, Laura Piveteau ${ }^{\dagger}$, Maksym V. Kovalenko ${ }^{\dagger *}$, and \\ Nicholas P. Stadie*\# \\ \#Department of Chemistry \& Biochemistry, Montana State University, Bozeman, Montana, United States \\ 'Laboratory of Inorganic Chemistry, Department of Chemistry and Applied Biosciences, ETH Zürich, Zürich, \\ Switzerland \\ ${ }^{\ddagger}$ Empa - Swiss Federal Laboratories for Materials Science \& Technology, Dübendorf, Switzerland
}

\begin{abstract}
A direct synthetic route to a tunable range of phosphorus-doped graphitic carbon materials is demonstrated via the reaction of benzene and phosphorus trichloride in a closed reactor at elevated temperatures $\left(800-1050{ }^{\circ} \mathrm{C}\right)$. Graphitic materials of continuously variable composition $\mathrm{PC}_{\mathrm{x}}$ up to a limit of approximately $\mathrm{x}=5$ are accessible, where phosphorus is incorporated both substitutionally within the graphite lattice and as stabilized $\mathrm{P}_{4}$ molecules. Higher temperatures result in a more ordered graphitic lattice while the maximum phosphorus content is not observed to diminish. Lower temperatures and higher initial phosphorus content in the reaction mixture are shown to correlate with higher structural disorder. Phosphorus incorporation within directlysynthesized $\mathrm{PC}_{\mathrm{x}}$, as both a substitutional dopant and in the form of interstitial, stabilized molecular $\mathrm{P}_{4}$, is demonstrated to occur with little oxygen contamination in the bulk $(<4$ at $\%)$, motivating promising future applications in fuel cells and alkali metal-ion batteries.
\end{abstract}

\section{INTRODUCTION}

Carbon and phosphorus are both highly abundant elements and form numerous well-known elemental crystal structures and amorphous allotropes that are stable (or meta-stable) at near ambient conditions. Phosphorus alone has at least five known crystalline polymorphs, including the most common, white phosphorus $\left(\alpha-\mathrm{P}_{4}\right)$, a highly unstable and volatile compound. Carbon exhibits perhaps the most versatile bonding of any element, and exists in at least six distinct crystalline forms, of which graphite is the thermodynamically stable phase at ambient conditions. Both phosphorus and carbon form distinct, stable binary compounds with almost every element of the periodic table; a surprising exception is with one another. ${ }^{1-2}$

Phosphorus doping of diamond and diamond-like carbon (DLC) films has been an active research pursuit for roughly three decades, and several synthesis methods have been reported.$^{3-6}$ Low concentrations $(<0.5$ at $\%)$ of phosphorus are known to yield polycrystalline, n-type semiconducting diamond films, which are of great interest for diamond-based electronic devices (e.g., as "solar blind" photodetectors). Carbonaceous materials with higher phosphorus content (up to $25 \mathrm{at} \%$ ) have also been reported, and found to be amorphous. ${ }^{8-}$

${ }_{11}$ This experimental work led to a series of dedicated theoretical studies of the crystal structure and stability of hypothetical binary carbon-phosphorus compounds, for which no bulk crystalline material has been discovered. ${ }^{12-16}$ Density functional theory (DFT) calculations predicted the existence of a defected zinc-blende structure of composition $\mathrm{P}_{4} \mathrm{C}_{3}{ }^{16}$ and the stability of solid solutions of phosphorus in graphitic structures for $\mathrm{P}_{4} \mathrm{C}_{3+8 \mathrm{n}}\left(\mathrm{n}=1,2,3\right.$, and 4). ${ }^{13} \mathrm{~A}$ semi-layered $\beta$ InS-like structure was also predicted by DFT calculations for the compound of composition $\mathrm{PC}_{3}$; in this structure, each phosphorus atom is bonded to three intralayer carbon atoms and forms a fourth interlayer bond to an adjacent phosphorus site (in tetrahedral geometry). ${ }^{14}$ Materials of composition PC have also been predicted, wherein all atoms are tetrahedrally coordinated and form a bilayer-type structure with alternating $\mathrm{P}$ and $\mathrm{C}$ lattice sites. ${ }^{15}$ Lastly, materials of composition $\mathrm{P}_{3} \mathrm{C}_{4}$, were found to have $\beta-C_{3} \mathrm{~N}_{4}$-like lowest-energy structures. ${ }^{16}$ None of these P-C binary materials have ever been synthesized in bulk, crystalline form. In the range of conditions explored in this laboratory up to and including this current report, high-phosphorus content P-C materials have been found only to occupy the graphitic region of the binary phase diagram.

Phosphorus doping of graphite and graphite-like carbon has been an emerging topic of recent research activity, but remains underexplored compared to other heteroatom dopants. Graphite is well-known to form solid solutions with many elements, especially neighboring boron and nitrogen, which can be exploited as a strategy to tune its electronic or other material properties. ${ }^{17-25}$ Investigations of such effects have largely been motivated by efforts to increase the capacity and tune the electrochemical binding of graphite toward alkali metal ions such as lithium, sodium, and potassium, for applications in batteries. $^{26-31}$ Meanwhile, the yearly consumption of high-purity graphite is rapidly increasing owing to increasing production of batteries for mobile and medium-scale stationary energy storage. ${ }^{32}$ As in diamond, phosphorus-doping of graphite would be expected to contribute a donor level to the band structure, imparting n-type semiconducting characteristics similarly to nitrogen. However, all previous work has revealed that obtaining P-doped graphitic materials where the phosphorus species remain unoxidized (as opposed to as phosphate) is a significant 
challenge. ${ }^{33}$ Furthermore, no tunable synthetic route to bulk graphitic materials doped with phosphorus has been reported. To this end, and with similarity to recent work on substitutional boron-inclusion within bulk graphitic materials, ${ }^{23}$ we hypothesized that widely tunable graphitic materials of composition $\mathrm{PC}_{\mathrm{x}}$ could be obtained directly from two commonly available liquid precursors: phosphorus trichloride and benzene.

In the search for a simple, direct synthesis route to graphitic $\mathrm{PC}_{\mathrm{x}}$, we have selected phosphorus trichloride, $\mathrm{PCl}_{3}$, as the dopant precursor. $\mathrm{PCl}_{3}$ is commonly used as a primary source of phosphorus in organic ${ }^{34}$ and inorganic synthesis, especially for nucleic acids and phosphorus(III) ligands (e.g., fluorous biphase catalysts and pincer ligands), ${ }^{35}$ and is generally preferred over highly toxic phosphine gas, $\mathrm{PH}_{3}$, in organic reactions. ${ }^{36} \mathrm{PCl}_{3}$ is itself synthesized from elemental phosphorus and chlorine gas, ${ }^{37}$ and is consumed on a massive industrial scale for the synthesis of glyphosate, the highest production agricultural chemical worldwide (production since 1974 exceeding $\left.8.6 \times 10^{9} \mathrm{~kg}\right){ }^{38}$ Phosphorus(III) can be made to bond with three phenyl groups by the reaction of $\mathrm{PCl}_{3}$ and chlorobenzene, yielding triphenylphosphine, a common, relatively air-stable organic reagent. Reactions of $\mathrm{PCl}_{3}$ with hydrocarbons is driven by the formation of $\mathrm{HCl}$, a wellexploited leaving group in organic chemistry. Benzene has been chosen as an ideal carbon precursor herein owing to its wide miscibility with $\mathrm{PCl}_{3}{ }^{39}$ and $\mathrm{sp}^{2}$-hybridized bonding.

In this work, we present a novel direct synthesis route to bulk, high phosphorus-content graphitic carbon $\left(\mathrm{PC}_{\mathrm{x}}\right)$ and describe its properties and potential applications. Oxygen-free liquid solutions containing the desired $\mathrm{P}: \mathrm{C}$ ratio corresponding to $x \geq 1$ were directly pyrolyzed in sealed, evacuated quartz tubes at elevated temperatures, and the resulting bulk products were investigated. The structure of the so-obtained materials varies from highly defected, turbostratic graphitic carbon to nanocrystalline graphite, as determined by X-ray diffraction (XRD) and Raman spectroscopy. The composition was estimated by X-ray dispersive (EDX) spectroscopy, and the phosphorus chemical environment was probed by a combination of techniques: X-ray photoelectron (XPS) and solid-state NMR spectroscopies. A majority of the phosphorus in the bulk was found to exist in P-P and P-C bonding environments, with detectable $\mathrm{P}-\mathrm{O}$ impurities near the material surface. A limit of phosphorus incorporation corresponding to $\sim \mathrm{PC}_{5}$ was suggested by the combined results from several independent techniques, indicating this composition to correspond to a model material for future investigations of the numerous expected applications of graphitic $\mathrm{PC}_{\mathrm{x}}$.

\section{EXPERIMENTAL SECTION}

Direct Synthesis of Bulk $\mathbf{P C}_{\mathbf{x}}$. A solution of phosphorus trichloride (99\%, Sigma Aldrich) and benzene (anhydrous $99.8 \%$, Sigma Aldrich) was charged into a quartz reaction tube ( $15 \mathrm{~cm}$ length, $0.9 \mathrm{~cm}$ inner diameter, closed at one end) inside a glovebox under inert atmosphere $\left(\mathrm{Ar},<0.5 \mathrm{ppm} \mathrm{H}_{2} \mathrm{O}\right.$, $<0.5$ ppm $\mathrm{O}_{2}$ ). The volume ratio of $\mathrm{PCl}_{3}: \mathrm{C}_{6} \mathrm{H}_{6}$ used to obtain a nominal composition " $\mathrm{PC}_{\mathrm{x}}$ " was determined as follows:

$$
V_{C_{6} H_{6}}=(0.1695 \cdot x) V_{P_{C l}}
$$

For example, a typical batch of nominal composition $\mathrm{PC}_{3}$ contained a solution of volume ratio 57.8:29.4 $\mu \mathrm{L}$. The open end of the tube was closed with a Swagelok ultra-torr adapter, removed from the glovebox, and placed in liquid nitrogen to solidify the precursor solution. In this state, the tube was connected to a stainless steel Schlenk line via the ultra-torr fitting, evacuated to $10^{-2} \mathrm{mbar}$, and then flame-sealed under vacuum.

The sealed tube was placed on an elevated rack at the center of the uniform temperature zone of a chamber furnace (Carbolite CWF 12/13) and heated to the temperature setpoint along a specified heating ramp via a programmable PID controller (Eurotherm 3216). The set temperature was held for 1-12 h, and then cooled to below $250{ }^{\circ} \mathrm{C}$ at which point the oven was opened and the tube removed. At ambient temperature, the tube was scored with a diamond-bladed saw and then carefully opened, releasing the over-pressure of gaseous reaction products into a fume hood (caution: fuming $\mathrm{HCl}$, along with pyrophoric reaction products, is released during this step). The solid product was collected and washed with deionized water, acetone, and then water again, and then dried in air at $80^{\circ} \mathrm{C}$ before further analysis. In some cases, the flakes adhered strongly to the quartz surface and could not be rinsed off; the reaction tubes were then filled with $10 \%$ aqueous HF and left standing for several hours before the product was collected.

Note: all materials in this work are referred to by their nominal composition, " $\mathrm{PC}_{\mathrm{x}}$ ", where $\mathrm{x}$ refers to the molar ratio of $\mathrm{P}: \mathrm{C}$ in the initial reaction mixture, and is found according to Equation 1.

Materials Characterization. Powder X-ray diffraction (XRD) measurements were performed on a Rigaku Ultima IV diffractometer using $\mathrm{Cu} K \alpha_{1}$ radiation $(\lambda=1.54 \AA)$ in reflection geometry. Samples were prepared for XRD by ultrasonication in acetone for $5 \mathrm{~min}$ and then dried at $80^{\circ} \mathrm{C}$. High-resolution scanning electron microscopy (SEM) of the (as-collected) free-standing flakes was performed using a Zeiss SUPRA 55VP microscope with a field emission electron source operated at $1.00 \mathrm{kV}$. Energy dispersive X-ray (EDX) spectroscopy of the as-collected flakes was performed using a JEOL JSM-6100 scanning electron microscope equipped with two Röntec XFlash 1000 detectors and operated at $20 \mathrm{kV}$. Samples were prepared for SEM and EDX by depositing the as-collected material onto an aluminum puck using conductive carbon tape, and were investigated without further coating. Raman spectroscopy of the free-standing flakes was performed using a Renishaw inVia confocal microscope equipped with a $514 \mathrm{~nm}$ Ar-ion laser at an incident power of $\sim 28 \mathrm{~mW}$.

X-ray photoelectron spectroscopy (XPS) was performed using a PHI 5600 spectrometer with monochromatic Al Ka radiation $(1486.6 \mathrm{eV})$ as the excitation source. Samples were prepared for XPS by pressing the as-collected flakes into indium foil. The vacuum chamber was maintained at a pressure of $\sim 10^{-9}$ mbar during measurements. The spectra were measured in duplicate with a resolution of $0.1 \mathrm{eV}$ and analyzed with RBD Instruments' AugerScan software using Gaussian-Lorentzian line shapes and a Shirley background. Depth profiles were obtained by sputtering a $2 \times 2 \mathrm{~mm}$ area of the flake surface with a $2 \mathrm{keV} \mathrm{Ar}^{+}$ion beam for specified periods of time (indicated in $\mathrm{min}$ ) between measurements. 
Solid-State NMR. ${ }^{31} \mathrm{P}$ and ${ }^{13} \mathrm{C}$ solid-state nuclear magnetic resonance (NMR) spectroscopy was performed using a Bruker $11.7 \mathrm{~T}$ spectrometer equipped with a triple resonance $2.5 \mathrm{~mm}$ solid-state probe head and an Avance III console. Samples were prepared for NMR by ultrasonication in acetone for 5 min, then dried at $80{ }^{\circ} \mathrm{C}$, and filled into a $2.5 \mathrm{~mm}$ zirconia rotor.

All experiments were performed at room temperature, either in static mode or while spinning the sample at $20 \mathrm{kHz}$ magicangle spinning (MAS) frequency. The ${ }^{31} \mathrm{P}$ chemical shift was determined with reference to $85 \% \mathrm{H}_{3} \mathrm{PO}_{4}$ in $\mathrm{D}_{2} \mathrm{O}$ and the ${ }^{13} \mathrm{C}$ chemical shift was determined with respect to $\mathrm{Si}\left(\mathrm{CH}_{3}\right)_{4}$. The number of transients recorded was 2000 for ${ }^{31} \mathrm{P}$ NMR experiments, and $16000-24000$ for ${ }^{13} \mathrm{C}$ NMR experiments. The classical Hahn echo pulse sequence was used for most ${ }^{31} \mathrm{P}$ NMR experiments, and a simple $30^{\circ}$-one-pulse excitation sequence was used for all ${ }^{13} \mathrm{C} \mathrm{NMR}$ and some ${ }^{31} \mathrm{P} \mathrm{NMR}$ experiments (as indicated). All spectra were acquired without decoupling. The recycle delay was set to $2 \mathrm{~s}$, the echo delay to $0.2 \mathrm{~ms}$, and the pulse length for $90^{\circ}$ flip angle experiments to 5 $\mu \mathrm{s}$ for ${ }^{31} \mathrm{P}$ NMR experiments. The recycle delay was set to $2 \mathrm{~s}$ with a $1.7 \mu \mathrm{s} 30^{\circ}$ pulse for ${ }^{13} \mathrm{C}$ NMR experiments.

\section{RESULTS}

Synthesis. Phosphorus incorporation within graphitic carbon is demonstrated to occur upon the pyrolysis of benzene in the presence of $\mathrm{PCl}_{3}$. This approach is referred to herein as the direct synthesis method, in analogy to the direct synthesis of boron-doped graphitic carbon materials using $\mathrm{BBr}_{3}$ as the boron precursor. ${ }^{23}$ Benzene and $\mathrm{PCl}_{3}$, like benzene and $\mathrm{BBr}_{3}$, are miscible liquids that can simply be combined under inert atmosphere to obtain high-purity stock solutions of any desired $\mathrm{P}: \mathrm{C}$ molar ratio. An appropriate volume of this solution is then charged into a quartz reaction tube whose volume is large enough to accommodate the eventual release of gaseous byproducts (likely a mixture of $\mathrm{HCl}, \mathrm{H}_{2}$, and/or $\mathrm{Cl}_{2}$ ) and sealed under vacuum. Upon heating, the gaseous precursor mixture is observed to undergo co-pyrolysis at temperatures above $550{ }^{\circ} \mathrm{C}$. It is notable that the simplicity of this approach allows the reaction to proceed with minimal chance for exposure to oxygen and loss of phosphorus from the system. The proposed (unbalanced) chemical reaction is as follows:

$$
\mathrm{C}_{6} \mathrm{H}_{6}+\mathrm{PCl}_{3} \rightarrow \mathrm{PC}_{x}+\mathrm{HCl}+\mathrm{H}_{2} / \mathrm{Cl}_{2}
$$

For higher $\mathrm{P}: \mathrm{C}$ ratios in the initial mixture, the production of $\mathrm{Cl}_{2}$ will be favored, while lower $\mathrm{P}: \mathrm{C}$ ratios favor $\mathrm{H}_{2}$. The solid product of the reaction consists of large metallic flakes and/or curled needle-like flakes of brilliant, dark luster. The product is recovered primarily from the center of the reaction tube for samples of high phosphorus content, while from both the inner walls and the center of the tube in the case of lower phosphorus content samples. The thickness of the flakes varies between 2-4 $\mu \mathrm{m}$ (see Figure 1). In many cases, spherical carbon-rich impurities $(\sim 3 \mu \mathrm{m}$ in diameter) can also be observed to cover one side of the as-obtained flakes, possibly due to preferential growth of the flakes toward the center of the reaction tube. ${ }^{21}$ The growth of such microspheres could not be reproducibly diminished by control of the temperature ramp when varied between $0.1-1{ }^{\circ} \mathrm{C} \mathrm{min}^{-1}$, and no discernible trend with respect to their formation could be established. In very high phosphorus-content samples, liquid white phosphorus droplets could be observed within the sealed reaction tubes after synthesis (see Figure S1) indicating incomplete incorporation of $\mathrm{P}$ within the graphitic solid product.

Structure. The structure of directly-synthesized $\mathrm{PC}_{\mathrm{x}}$ was investigated primarily by X-ray diffraction (XRD) and Raman spectroscopy. The XRD patterns of all so-obtained $\mathrm{PC}_{\mathrm{x}}$ materials show a dominant, broad reflection centered at $2 \theta=$ $23-26^{\circ}$ (d-spacing of $3.45-3.85 \AA$ ) corresponding to the (002) reflection in graphite (see Figure 2). The broad XRD reflections (up to $\mathrm{FWHM}=10^{\circ}$ ) indicate that the majority of the directly-synthesized materials are highly disordered, with typical characteristics of turbostratic graphitic carbons obtained at temperatures of $<1200{ }^{\circ} \mathrm{C}$. ${ }^{4-41}$ Samples prepared at higher temperatures generally exhibit a narrower (002) reflection, with the narrowest (and therefore most ordered) material being $\mathrm{PC}_{5}$ synthesized at $1050{ }^{\circ} \mathrm{C}$. At both temperatures investigated, an abrupt structural transition is observed as a function of increasing (nominal) phosphorus content: between $\mathrm{PC}_{5}$ and $\mathrm{PC}_{4}$ for samples synthesized at 800 ${ }^{\circ} \mathrm{C}$, and between $\mathrm{PC}_{4}$ and $\mathrm{PC}_{3}$ for samples synthesized at 1050 ${ }^{\circ} \mathrm{C}$. The peak center abruptly shifts to lower angle upon this transition (shown by the purple dashed lines in Figure 2), and the peak width increases significantly. In general, the peak center of all materials indicates a larger d-spacing than that of crystalline graphite $(3.35 \AA)$, but the angular position of this reflection is known to have a complex dependence on turbostratic structure. ${ }^{41}$ For samples synthesized at $800{ }^{\circ} \mathrm{C}$, the average d-spacing is $3.56 \AA$ until abrupt transition to $3.85 \AA$ at $\mathrm{x} \leq 4$. For samples synthesized at $1050{ }^{\circ} \mathrm{C}$, the average $\mathrm{d}$ spacing is $3.45 \AA$ until abrupt transition to continuously larger d-spacings at $\mathrm{x} \leq 3$.

Figure 1. SEM micrographs of typical bulk $\mathrm{PC}_{\mathrm{x}}$ materials obtained by direct synthesis from $\mathrm{PCl}_{3}$ and benzene. The dark metallic flakes vary in thickness between 2-4 $\mu \mathrm{m}$.

Figure 2. XRD patterns of (top) $\mathrm{PC}_{\mathrm{x}}$ synthesized at $800{ }^{\circ} \mathrm{C}$ for $1 \mathrm{~h}$, varying nominal composition between $1 \leq \mathrm{x} \leq 12$, and (bottom) $\mathrm{PC}_{\mathrm{x}}$ synthesized at $1050{ }^{\circ} \mathrm{C}$ for $1 \mathrm{~h}$, varying nominal composition between $1 \leq \mathrm{x} \leq 12$. Crystalline graphite (dotted line) is also shown for comparison.

The Raman spectra of directly-synthesized $\mathrm{PC}_{\mathrm{x}}$ materials exhibit the typical features of disordered or nanocrystalline graphitic carbon (see Figure S2) ${ }^{42-43}$ All spectra show a prominent band centered at $1580-1590 \mathrm{~cm}^{-1}$ (the "G mode" corresponding to $\mathrm{E}_{2 \mathrm{~g}}$ phonons in graphite), a prominent band centered at $1350-1360 \mathrm{~cm}^{-1}$ (the "D mode" corresponding to $A_{1 g}$ breathing vibrations of 6-membered rings, allowed only in the presence of disorder in the graphite lattice) and several broad features in the second-order region between 2300-3300 $\mathrm{cm}^{-1}$. The intensity of the $\mathrm{D}$ band indicates significant disorder in the graphitic structure of $\mathrm{PC}_{\mathrm{x}}$, which could merely be the result of lowered symmetry due to the inclusion of phosphorus within the lattice; however, XRD results point to significant overall structural disorder due to incomplete graphitization at the relatively low temperature of synthesis employed in this work. Importantly, no Raman bands corresponding to P-P bonding networks as found in any of the common allotropes of 
elemental phosphorus are observed ${ }^{44-45}$ (although this result does not rule out the presence of P-P bonded molecular intercalant species $^{46}$ ).

Raman spectra of $\mathrm{PC}_{3}$ and $\mathrm{PC}_{5}$ synthesized at 800 and 1050 ${ }^{\circ} \mathrm{C}$, materials of compositions above and below the abrupt transitions detected in XRD measurements, are compared in Figure 3. For samples synthesized at $800{ }^{\circ} \mathrm{C}$, no significant difference is observed between the "more ordered," narrower interlayer spaced graphitic carbon (i.e., $\mathrm{x} \geq 5$ ) and the more disordered, wider spaced materials of higher nominal phosphorus content (i.e., $x \leq 4$ ). All of these materials exhibit very broad, overlapping $D$ and $G$ bands, with an intensity ratio $\left(\mathrm{I}_{\mathrm{D}} / \mathrm{I}_{\mathrm{G}}\right)$ of $0.90-0.95$ that does not depend significantly on phosphorus content (see Figure S3).

However, for samples synthesized at $1050{ }^{\circ} \mathrm{C}$, several significant differences in the Raman spectra are observed as a function of increasing phosphorus content, especially between $\mathrm{PC}_{5}$ and $\mathrm{PC}_{3}$. At low nominal phosphorus content (i.e., $\mathrm{x} \geq 5$ ), the Raman spectrum exhibits $D$ and $G$ bands that are narrower and nearly baseline-resolved in addition to well-defined second-order Raman peaks, typical of more ordered nanocrystalline graphite. ${ }^{43}$ The intensity ratio between the $\mathrm{D}$ and $\mathrm{G}$ bands $\left(\mathrm{I}_{\mathrm{D}} / \mathrm{I}_{\mathrm{G}}\right)$ varies between $0.67-0.94$, which for many compositions is significantly lower than in materials synthesized at $800{ }^{\circ} \mathrm{C}$, and is strongly dependent on nominal phosphorus content (see Figure S3).

The measured $\mathrm{I}_{\mathrm{D}} / \mathrm{I}_{\mathrm{G}}$ values, in combination with a $\mathrm{G}$ band position of $\sim 1580-1590 \mathrm{~cm}^{-1}$, indicate that all directlysynthesized $\mathrm{PC}_{\mathrm{x}}$ materials demonstrate graphitic structure intermediate between that of nanocrystalline and ordered graphite (within "stage 1" in the Ferrari and Robertson threestage model) as opposed to between nanocrystalline graphite and amorphous carbon. ${ }^{43}$ The ${ }^{13} \mathrm{C}$ MAS NMR spectra of directly-synthesized $\mathrm{PC}_{\mathrm{x}}$ are also consistent with polycrystalline graphitic carbon (see Figure S4), showing a broad feature centered at $\delta=\sim 115 \mathrm{ppm}$ that is indicative of exclusively $\mathrm{sp}^{2}$-hybridization.

Figure 3. Raman spectra of $\mathrm{PC}_{3}$ and $\mathrm{PC}_{5}$ synthesized at 800 ${ }^{\circ} \mathrm{C}$ and $1050{ }^{\circ} \mathrm{C}$. Crystalline graphite (black) is shown for comparison.

Composition. The elemental composition of directlysynthesized $\mathrm{PC}_{\mathrm{x}}$ was investigated herein by a combination of energy-dispersive X-ray spectroscopy (EDX) and X-ray photoelectron spectroscopy (XPS), as "bulk" and "surface" methods, respectively. The results of EDX analysis of all $\mathrm{PC}_{\mathrm{x}}$ materials synthesized in this work are shown in Figure 4. The phosphorus content is measured to vary from $4-16$ at $\%$ across all samples measured, and does not depend on the temperature of synthesis. An upper limit of phosphorus incorporation within graphitic $\mathrm{PC}_{\mathrm{x}}$ is observed to occur in samples of nominal composition corresponding to $\mathrm{x} \leq 3$. In other words, higher $\mathrm{P}: \mathrm{C}$ ratios in the initial reaction mixture $\left(\mathrm{PC}_{3}, \mathrm{PC}_{2}\right.$, and $\mathrm{PC}$ nominal compositions) do not lead to higher phosphorus content in the resulting solid product. A roughly linear relationship exists between the nominal and measured phosphorus content in materials of lower nominal composition (corresponding to $\mathrm{x} \geq 4$ ). The interaction depth corresponding to $\mathrm{K}$-shell electrons is $\sim 5 \mu \mathrm{m}$ in carbonaceous materials (considering the operating voltage of $20 \mathrm{kV}),{ }^{47}$ which implies that EDX spectroscopy is effectively a bulk measurement for the 2-4 $\mu \mathrm{m}$ thick flakes investigated in this work. The lack of a binary P-C reference material prevents the correction of EDX measurements for effects such as carbon tape contamination. Oxygen was also detected along with trace amounts of chlorine in all samples analyzed.

Figure 4. Elemental composition of $\mathrm{PC}_{\mathrm{x}}$ samples synthesized at $800{ }^{\circ} \mathrm{C}$ (filled symbols) and $1050{ }^{\circ} \mathrm{C}$ (empty symbols) as determined by EDX spectroscopy. The data are fitted (dashed purple line) in two regions as a visual guide, and compared to an ideal 1:1 dependence (dashed gray line).

The oxygen content of directly-synthesized $\mathrm{PC}_{\mathrm{x}}$ was investigated in detail by XPS depth-profiling analysis. Measurements obtained at the surface of the as-synthesized flakes showed a significant content of oxygen species for all materials investigated. However, upon brief argon ion sputtering of the surface (e.g., $2 \mathrm{~min}$ ), the oxygen content was observed to significantly diminish or disappear. Survey scans for $\mathrm{PC}_{5}$ synthesized at $800{ }^{\circ} \mathrm{C}$ are shown in Figure $\mathrm{S} 5$ as a function of sputtering time (i.e., depth below the sample surface). In this representative example, the total oxygen content is $8.7 \mathrm{at} \%$ at the surface, 2.6 at $\%$ after 2 min sputtering time, and 2.2 at $\%$ after 20 min sputtering time, corresponding to a final depth of $\sim 80 \mathrm{~nm}$ below the original surface. The overall phosphorus content determined by XPS analysis is significantly lower than that determined by EDX analysis (e.g., 3.8 at \% in $\mathrm{PC}_{5}$ ) which indicates lower phosphorus occupation near the surface of the flakes than in the bulk.

Phosphorus Environment. The nature of phosphorus inclusion within directly-synthesized $\mathrm{PC}_{\mathrm{x}}$ was examined herein by a combination of solid-state NMR spectroscopy and X-ray photoelectron spectroscopy (XPS) analysis. A series of ${ }^{31} \mathrm{P}$ NMR spectra corresponding to $\mathrm{PC}_{\mathrm{x}}$ synthesized at $1050{ }^{\circ} \mathrm{C}$ are shown in Figure 5. Three distinct phosphorus environments are observed: a sharp signal at $\delta=\sim 0 \mathrm{ppm}$ corresponding to tetrahedral $\mathrm{P}-\mathrm{O}$ environments (i.e., phosphates), a broad signal from $\delta=200$ to -100 ppm corresponding to trigonal planar P$\mathrm{C}$ environments (as in P-substituted graphite), and an intense signal at $\delta=-530 \mathrm{ppm}$ corresponding to electron-rich, tetrahedral $\mathrm{P}_{4}$ molecules (as in white phosphorus). Notably, in materials of composition corresponding to $\mathrm{x} \geq 5$, the $\mathrm{P}-\mathrm{O}$ chemical environments are barely detected above noise; a majority of the phosphorus exists in the form of P-C or P-P bonded species. In materials of higher nominal phosphorus content, P-O species are readily detected in addition to P-P species, while the $\mathrm{P}-\mathrm{C}$ species become more difficult to detect owing to overlap of the P-O and P-C signals (see Figure S7).

The origin of the width of the broad signal corresponding to $\mathrm{P}-\mathrm{C}$ environments in the ${ }^{31} \mathrm{P}$ NMR spectra of directlysynthesized $\mathrm{PC}_{\mathrm{x}}$ was subsequently examined by two methods, as shown in Figure 6. In the first set of experiments, the role of homogeneous line broadening such as that originating from dynamics or relaxation effects was investigated. A spin echo experiment ( $0.2 \mathrm{~ms}$ echo time), also known as a Hahn echo, was performed in order to refocus inhomogeneous interactions, thereby filtering out any homogeneous 
contributions to the linewidth larger than $5 \mathrm{kHz} ;^{48}$ this experiment was then compared to a typical single $30^{\circ}$ pulse (zg30) sequence experiment. No significant difference in linewidth was detected, indicating no significant contribution to the broadening of the P-C signal from homogeneous effects. This implies that the broad linewidth of this signal is likely due to one of several heterogeneous broadening effects, such as that of site disorder, dipolar coupling, or chemical shift anisotropy (CSA).

In a second set of experiments, the contributions to broadening specifically from dipolar coupling and CSA were investigated. An experiment performed under static conditions was compared to an experiment under rapid spinning of the sample about the magic angle $\left(54.7^{\circ}\right)$, both with the same (zg30) pulse sequence. ${ }^{49-50}$ In this case, a small decrease in linewidth was detected under MAS conditions, implying that site disorder is likely the main cause of broadening in the P-C resonance. This narrowing is well explained by the averaging of the CSA which must be of significant magnitude due to the layered structure of directly-synthesized graphitic $\mathrm{PC}_{\mathrm{x}}$. The results of these experiments (in combination with the results of Raman spectroscopy) can also be used to rule out a significant presence of red phosphorus in graphitic $\mathrm{PC}_{\mathrm{x}}$, which would induce a broad, inhomogeneous signal around 50 ppm. ${ }^{51-52}$

$\mathrm{X}$-ray photoelectron spectroscopy is a complementary technique for comparison to solid-state NMR, allowing the identification and quantification of different chemical species at near the material surface instead of within the bulk. ${ }^{53}$ In combination with ion beam milling, XPS can also provide a profile of these species as a function of depth below the surface. Spectra of directly-synthesized $\mathrm{PC}_{\mathrm{x}}$ were measured at three depths: at the surface of the as-synthesized flake, after 2 min of argon ion sputtering, and after $20 \mathrm{~min}$ of argon ion sputtering (e.g., see Figure S5). In all materials investigated, after only 2

Figure 5. ${ }^{31} \mathrm{P}$ MAS NMR spectra of $\mathrm{PC}, \mathrm{PC}_{3}, \mathrm{PC}_{5}$, and $\mathrm{PC}_{8}$ synthesized at $1050{ }^{\circ} \mathrm{C}$, showing three distinct phosphorus environments within the bulk of the material: $\mathrm{P}_{4}(-530 \mathrm{ppm})$, P-C species (200 to $-100 \mathrm{ppm})$, and phosphate ( $\sim 0 \mathrm{ppm})$.

min of sputtering, the phosphorus is mainly present as bonded to other phosphorus $\left({ }^{31} \mathrm{P}\right.$ NMR results indicate this to be $\left.\mathrm{P}_{4}\right)$ and to carbon $\left({ }^{31} \mathrm{P}\right.$ NMR results indicate this to be trigonal planar P-C bonding), as shown in Figure S6. A significant amount of the phosphorus at the unsputtered surface, however, is found to be oxidized (varying between 18-75\% in different samples). This is somewhat to be expected since white phosphorus reacts spontaneously in contact with oxygen and even trivalent phosphorus incorporated in the graphitic lattice at the surface could potentially undergo oxidation into a pentavalent species.

The bulk material bonding environments of phosphorus and their relative amounts within $\mathrm{PC}_{3}$ and $\mathrm{PC}_{5}$ synthesized at 800 ${ }^{\circ} \mathrm{C}$ were investigated by XPS, after $20 \mathrm{~min}$ of argon ion sputtering (Figure 7). Both materials were found to contain the same three distinct contributions to phosphorus bonding in a similar distribution: $\sim 71 \%$ P-P bonding environments (at 129.7-8 and 130.5-6 eV), 27\% P-C bonding environments (at
131.2-4 and 132.0-2 eV), and the balance (2-4\%) P-O environments (at $>133 \mathrm{eV}$ ). ${ }^{54}$ The six corresponding peaks (resulting from spin-orbit splitting) are highly overlapping, but each contribution to the XPS spectrum is justified by comparison to the solid-state NMR results (where the same three bonding environments were independently observed). Both $\mathrm{P}-\mathrm{C}$ and $\mathrm{P}-\mathrm{P}$ bonding are consistent with many of the theoretical $\mathrm{PC}_{\mathrm{x}}$ structures reported, especially the $\beta$-InS-like structure expected for carbon-rich compositions. ${ }^{11,16}$ Only negligible difference in the distribution of phosphorus bonding environments was detected between $\mathrm{PC}_{3}$ and $\mathrm{PC}_{5}$ synthesized at $800{ }^{\circ} \mathrm{C}$.

\section{DISCUSSION}

The direct synthesis of bulk phosphorus-doped carbon described herein is a simple (one-step, one-pot), easily tunable, and cost-effective method to obtain binary P-C graphitic materials of varying composition. This method is clearly distinguished from the majority of previous phosphorus doping or incorporation strategies that rely on phosphate-based precursors (e.g., phosphoric acid, ${ }^{55-58}$ phytic acid, ${ }^{59}$ or monoammonium phosphate ${ }^{60}$ ); the use of $\mathrm{PCl}_{3}$ provides a strictly oxygen-free phosphorus source that may also be promising for the P-doping of diamond-like and porous carbon materials. While oxygen contamination may not be possible to completely eliminate at the material surface (resulting from workup in air), this work has shown that little or no oxygen contamination of the bulk is accessible to a wide range of composition of graphitic carbon $\mathrm{PC}_{\mathrm{x}}$ materials. This may be a promising first step toward obtaining a bulk, crystalline, binary P-C compound for comparison with predicted structures.

Interestingly, the degree of ordering and average interlayer spacing of directly-synthesized $\mathrm{PC}_{\mathrm{x}}$ materials differ significantly as a function of synthesis temperature and nominal $\mathrm{P}: \mathrm{C}$ ratio. The average interlayer spacing, as measured by XRD, varies from 3.45-3.85 $\AA$, corresponding to a range between $3-15 \%$ larger than pristine graphite. In samples synthesized at high-temperatures, significantly higher structural ordering is evidenced by Raman spectroscopy for compositions up to $\mathrm{x}=4$, whereupon further incorporation of phosphorus leads to severe disordering of the graphitic lattice. This distinct variability of structural character in $\mathrm{PC}_{\mathrm{x}}$ is in notable contrast to directly-synthesized boron-doped graphitic carbon $\left(\mathrm{BC}_{\mathrm{x}}\right)$ which exhibits highly disordered structure (evidenced by XRD and Raman spectroscopy) at all compositions and synthesis parameters investigated. ${ }^{23}$ The atomic diameter mismatch between phosphorus and carbon is much larger than that between boron and carbon, and phosphorus might therefore have been expected to enact a larger strain on the graphitic lattice; this was not observed to be the case.

Figure 6. ${ }^{31} \mathrm{P}$ NMR spectra of $\mathrm{PC}_{5}$ synthesized at $1050{ }^{\circ} \mathrm{C}$ under different experimental conditions: a Hahn echo experiment under $20 \mathrm{kHz}$ MAS (light green), a single $30^{\circ}$ pulse (zg30) under $20 \mathrm{kHz}$ MAS (light blue), and a single $30^{\circ}$ pulse (zg30) in static mode (dark blue). 
An unexpected characteristic of phosphorus doping in graphitic carbon revealed by XPS and solid-state NMR results is the existence of at least two distinct phosphorus environments in bulk $\mathrm{PC}_{\mathrm{x}}$ : substitutional $\mathrm{P}-\mathrm{C}$ type and molecular $\mathrm{P}_{4}(\mathrm{P}-\mathrm{P})$ type. In comparison to boron doping of graphitic carbon, where the boron exists exclusively as a substitutional dopant within the graphitic lattice, ${ }^{23}$ phosphorus therefore causes a less significant overall disruption to the graphitic lattice. That is, until the limit on overall phosphorusincorporation is reached, whereupon overwhelming disorder is effected on the graphitic lattice. Despite this difference, a similar range in total dopant content is observed for boronand phosphorus-doped graphic carbon $\left(\mathrm{x} \geq 5\right.$ for $\mathrm{PC}_{\mathrm{x}}$ compared to $\mathrm{x} \geq 3$ for $\mathrm{BC}_{\mathrm{x}}$ ).

The wide compositional tunability accessible in directlysynthesized $\mathrm{PC}_{\mathrm{x}}$ is not appreciably limited by increased synthesis temperatures of up to $1050{ }^{\circ} \mathrm{C}$, as shown in Figure 4. A maximum of 16 at $\%$ phosphorus was detected in samples of (nominal composition) $\mathrm{PC}_{3}$, which corresponds to a measured stoichiometry of $\sim \mathrm{PC}_{5}$. The difference between the nominal and measured content is attributable at least in part to systematic error; additional carbon is inherently present in the EDX sample environment due to the carbon-based adhesive used to mount the samples. This maximum content of phosphorus, if properly corrected for, could thus correspond to an actual composition of up to $\mathrm{x}=3$, which is close to the limit previously reported for amorphous $\mathrm{PC}_{\mathrm{x}}$ films. ${ }^{14}$ Beyond this apparent limit, directly-synthesized $\mathrm{PC}_{\mathrm{x}}$ undergoes large structural changes consistent with reduced structural ordering, an abrupt shift to wider interlayer spacing, and higher phosphate content as detected by ${ }^{31} \mathrm{P}$ NMR. Together, these results suggest that a model material for future investigations lies between $5 \geq x \geq 3$. Such a high content of phosphorus, where a significant quantity exists as substitutional dopant within the graphitic lattice, is expected to be especially promising for application in the electrocatalysis of the oxygen reduction reaction $(\mathrm{ORR})^{56,59,}$ 61-67 and other catalytic processes. ${ }^{68-69}$

Remarkably, all $\mathrm{PC}_{\mathrm{x}}$ materials investigated herein contain a significant quantity of phosphorus in the form of $\mathrm{P}_{4}$ tetrahedra despite being handled extensively in air and at elevated temperatures during workup. The ${ }^{31} \mathrm{P}$ chemical shift of this species is unmistakable, occurring at $-530 \mathrm{ppm}$, extremely upfield and sharp compared to the broad signal corresponding to P-C environments (Figure 5). Its shift is also seen to vary systematically downfield as a function of increasing phosphorus content, although this may simply be due to the presence of water or other solvents. ${ }^{70}$ While it cannot presently be deduced whether these $\mathrm{P}_{4}$ environments exist as large or small clusters, or as isolated molecules, the mere presence of stabilized $\mathrm{P}_{4}$ may be of interest in several applications. ${ }^{71}$ In particular, phosphorus is a high-capacity theoretical anode material for both lithium- and sodium-ion batteries, but cannot be used as a bulk electrode material owing to hazards related to its stability, poor conductivity, and excessive volume changes during charge and discharge (e.g., the unit cell volume of $\mathrm{Li}_{3} \mathrm{P}$ is $400 \%$ of that of white phosphorus). ${ }^{72-77} \mathrm{~A}$ material containing a significant content of $\mathrm{P}_{4}$ in stabilized form, in which the volume expansion would also be appropriately buffered, may be able to overcome this obstacle. ${ }^{78-79}$ Previous attempts to
Figure 7. XPS spectra of $\mathrm{PC}_{3}$ and $\mathrm{PC}_{5}$ synthesized at $800{ }^{\circ} \mathrm{C}$ in the $\mathrm{P} 2 \mathrm{p}$ region (black symbols), showing contributions primarily from P-P (blue lines) and P-C (green lines) bonding environments in the material bulk (i.e., after 20 min of argon ion sputtering).

synthesize bulk graphitic materials of composition $\mathrm{PC}_{3}$, via a molecular tiling strategy, ${ }^{33}$ also witnessed the formation of stabilized $\mathrm{P}_{4}$ species; however, these materials contained an extremely high oxygen content ( $\geq 80 \%$ P-O species) at all depths within the bulk. The work reported herein, where oxygen contamination was greatly reduced (effectively eliminated in the material bulk), serves as new evidence that the presence of pristine, stabilized $\mathrm{P}_{4}$ can indeed be preserved even at very high relative content $(>10$ at $\%$ on a total material basis) within bulk graphitic carbon stored under ambient conditions. The implications and possibility for exploitation of this result remain to be explored in future work.

\section{CONCLUSIONS}

A novel synthesis route to phosphorus-doped graphitic carbon, $\mathrm{PC}_{\mathrm{x}}$, via the direct pyrolysis of two readily available, liquid precursors has been presented. Varying either the nominal material composition, $\mathrm{x}$, or the temperature of synthesis was shown to result in significant structural changes, where higher temperatures (up to $1050{ }^{\circ} \mathrm{C}$ ) and lower initial phosphorus content (up to a limit of $\mathrm{x}=\sim 5$ ) correspond to higher graphitic ordering. The phosphorus incorporated within graphitic $\mathrm{PC}_{\mathrm{x}}$ was found to exist in two important chemical environments: as substitutional $\mathrm{P}$ within the graphitic lattice and as free, stabilized $\mathrm{P}_{4}$ molecules, likely in interstitial voids between graphitic layers below the material surface. Future work must be undertaken to determine optimal synthesis conditions to achieve solely one type of phosphorus inclusion or the other; all directly-synthesized materials investigated herein consisted of both phosphorus species in coexistence. Only a small fraction of the bulk phosphorus content was detected to be bonded to oxygen $(<4$ at $\%)$. The material of nominal composition $\mathrm{PC}_{5}$ has been identified as a model material for future investigations, e.g., as an electrode material for alkali metal-ion batteries and for electrocatalysis.

\section{ASSOCIATED CONTENT}

Supporting Information. Additional materials characterization and XPS peak-fitting analysis. This material is available free of charge via the Internet at http://pubs.acs.org.

\section{AUTHOR INFORMATION}

\section{Corresponding Author}

*nicholas.stadie@montana.edu

\section{Author Contributions}

The manuscript was written through contributions of all authors.

\section{ACKNOWLEDGMENT}

We thank Julie Muretta for assistance with SEM investigations, Manjula Nandasiri for performing XPS measurements, and Gary Wyss for assistance with XRD and Raman measurements. This 
work was financially supported by start-up funding provided by Montana State University.

\section{REFERENCES}

(1) Greenwood, N. N.; Earnshaw, A., Chemistry of the Elements. Elsevier: 2012.

(2) Li, Z.; Chen, X.; Andrada, D. M.; Frenking, G.; Benkö, Z.; Li, Y.; Harmer, J. R.; Su, C. Y.; Grützmacher, H., $(\mathrm{L})_{2} \mathrm{C}_{2} \mathrm{P}_{2}$ : Dicarbondiphosphide Stabilized by N-Heterocyclic Carbenes or Cyclic Diamido Carbenes. Angew. Chem. Int. Ed. 2017, 56 (21), 5744-5749.

(3) Okano, K.; Kiyota, H.; Iwasaki, T.; Nakamura, Y.; Akiba, Y.; Kurosu, T.; Iida, M.; Nakamura, T., Synthesis of N-Type Semiconducting Diamond Film Using Diphosphorus Pentaoxide as the Doping Source. Appl. Phys. A 1990, 51 (4), 344-346.

(4) Bohr, S.; Haubner, R.; Lux, B., Influence of Phosphorus Addition on Diamond CVD. Diam. Relat. Mater. 1995, 4 (2), 133 144.

(5) Tsang, R. S.; May, P. W.; Ashfold, M. N. R.; Rosser, K. N., Influence of Phosphine on the Diamond Growth Mechanism: A Molecular Beam Mass Spectrometric Investigation. Diam. Relat. Mater. 1998, 7 (11), 1651-1656.

(6) Koizumi, S.; Kamo, M.; Sato, Y.; Mita, S.; Sawabe, A.; Reznik, A.; Uzan-Saguy, C.; Kalish, R., Growth and Characterization of Phosphorus Doped N-Type Diamond Thin Films. Diam. Relat. Mater. 1998, 7 (2-5), 540-544.

(7) Nesladek, M., Conventional N-Type Doping in Diamond: State of the Art and Recent Progress. Semicond. Sci. Technol. 2005, 20 (2), R19.

(8) Kuo, M. T.; May, P. W.; Gunn, A.; Ashfold, M. N. R.; Wild, R. K., Studies of Phosphorus Doped Diamond-Like Carbon Films. Diam. Relat. Mater. 2000, 9 (3), 1222-1227.

(9) Pearce, S. R. J.; May, P. W.; Wild, R. K.; Hallam, K. R.; Heard, P. J., Deposition and Properties of Amorphous Carbon Phosphide Films. Diam. Relat. Mater. 2002, 11 (3-6), 1041-1046.

(10) Fuge, G. M.; May, P. W.; Rosser, K. N.; Pearce, S. R. J.; Ashfold, M. N. R., Laser Raman and X-Ray Photoelectron Spectroscopy of Phosphorus Containing Diamond-Like Carbon Films Grown by Pulsed Laser Ablation Methods. Diam. Relat. Mater. 2004, 13 (4), 1442-1448.

(11) Hart, J. N.; May, P. W.; Allan, N. L.; Hallam, K. R.; Claeyssens, F.; Fuge, G. M.; Ruda, M.; Heard, P. J., Towards New Binary Compounds: Synthesis of Amorphous Phosphorus Carbide by Pulsed Laser Deposition. J. Solid State Chem. 2013, 198, 466-474.

(12) Claeyssens, F.; Allan, N. L.; May, P. W.; Ordejón, P.; Oliva, J. M., Solid Phosphorus Carbide? Chem. Commun. 2002, (21), 2494-2495.

(13) Claeyssens, F.; Oliva, J. M.; May, P. W.; Allan, N. L., Binary Phosphorus-Carbon Compounds: The Series $\mathrm{P}_{4} \mathrm{C}_{3+8 n}$. Int. J. Quantum Chem. 2003, 95 (4-5), 546-553.

(14) Claeyssens, F.; Fuge, G. M.; Allan, N. L.; May, P. W.; Ashfold, M. N. R., Phosphorus Carbides: Theory and Experiment. Dalton T. 2004, 3085-3092.

(15) Claeyssens, F.; Fuge, G. M.; Allan, N. L.; May, P. W.; Pearce, S. R. J.; Ashfold, M. N. R., Phosphorus Carbide Thin Films: Experiment and Theory. Appl. Phys. A-Mater 2004, 79 (4-6), $1237-$ 1241.

(16) Claeyssens, F.; Hart, J. N.; Allan, N. L.; Oliva, J. M., Solid Phases of Phosphorus Carbide: An Ab Initio Study. Phys. Rev. B 2009, 79 (13).

(17) Lowell, C. E., Solid Solution of Boron in Graphite. J. Am. Ceram. Soc. 1967, 50 (3), 142-144.

(18) Kouvetakis, J.; Kaner, R. B.; Sattler, M. L.; Bartlett, N., A Novel Graphite-Like Material of Composition $\mathrm{BC}_{3}$, and NitrogenCarbon Graphites. J Chem. Soc. Chem. Comm. 1986, (24), 17581759.
(19) Kaner, R. B.; Kouvetakis, J.; Warble, C. E.; Sattler, M. L.; Bartlett, N., Boron-Carbon-Nitrogen Materials of Graphite-Like Structure. Mater. Res. Bull. 1987, 22 (3), 399-404.

(20) Sekine, T.; Kanda, H.; Bando, Y.; Yokoyama, M.; Hojou, K., A Graphitic Carbon Nitride. J. Mater. Sci. Lett. 1990, 9 (12), 1376-1378.

(21) King, T. C.; Matthews, P. D.; Holgado, J. P.; Jefferson, D. A.; Lambert, R. M.; Alavi, A.; Wright, D. S., A Single-Source Route to Bulk Samples of $\mathrm{C}_{3} \mathrm{~N}$ and the Co-Evolution of Graphitic Carbon Microspheres. Carbon 2013, 64, 6-10.

(22) King, T. C.; Matthews, P. D.; Glass, H.; Cormack, J. A.; Holgado, J. P.; Leskes, M.; Griffin, J. M.; Scherman, O. A.; Barker, P. D.; Grey, C. P., Theory and Practice: Bulk Synthesis of $\mathrm{C}_{3} \mathrm{~B}$ and Its $\mathrm{H}_{2}$-and Li-Storage Capacity. Angew. Chem. Int. Ed. 2015, 54 (20), 5919-5923.

(23) Stadie, N. P.; Billeter, E.; Piveteau, L.; Kravchyk, K. V.; Döbeli, M.; Kovalenko, M. V., Direct Synthesis of Bulk BoronDoped Graphitic Carbon. Chem. Mater. 2017, 29 (7), 3211-3218.

(24) Larkins, G.; Vlasov, Y.; Holland, K., Evidence of Superconductivity in Doped Graphite and Graphene. Supercond. Sci. Technol. 2015, 29 (1), 015015.

(25) Way, B. M.; Dahn, J. R.; Tiedje, T.; Myrtle, K.; Kasrai, M., Preparation and Characterization of $\mathrm{B}_{\mathrm{x}} \mathrm{C}_{1-\mathrm{x}}$ Thin-Films with the Graphite Structure. Phys. Rev. B 1992, 46 (3), 1697-1702.

(26) Way, B. M.; Dahn, J. R., The Effect of Boron Substitution in Carbon on the Intercalation of Lithium in $\operatorname{Li}_{\mathrm{x}}\left(\mathrm{B}_{2} \mathrm{C}_{1-z}\right)_{6} . J$. Electrochem. Soc. 1994, 141 (4), 907-912.

(27) Reddy, A. L. M.; Srivastava, A.; Gowda, S. R.; Gullapalli, H.; Dubey, M.; Ajayan, P. M., Synthesis of Nitrogen-Doped Graphene Films for Lithium Battery Application. ACS Nano 2010, 4 (11), 6337-6342.

(28) Zhang, C.; Mahmood, N.; Yin, H.; Liu, F.; Hou, Y., Synthesis of Phosphorus-Doped Graphene and Its Multifunctional Applications for Oxygen Reduction Reaction and Lithium Ion Batteries. Adv. Mater. 2013, 25 (35), 4932-4937.

(29) Joshi, R. P.; Ozdemir, B.; Barone, V.; Peralta, J. E., Hexagonal $\mathrm{BC}_{3}$ : A Robust Electrode Material for $\mathrm{Li}, \mathrm{Na}$, and $\mathrm{K}$ Ion Batteries. J. Phys. Chem. Lett. 2015, 6, 2728-2732.

(30) Kuzubov, A. A.; Fedorov, A. S.; Eliseeva, N. S.; Tomilin, F. N.; Avramov, P. V.; Fedorov, D. G., High-Capacity Electrode Material $\mathrm{BC}_{3}$ for Lithium Batteries Proposed by $\mathrm{Ab}$ Initio Simulations. Phys. Rev. B 2012, 85 (19), 195415.

(31) Bhauriyal, P.; Mahata, A.; Pathak, B., Hexagonal $\mathrm{BC}_{3}$ Electrode for a High-Voltage Al-Ion Battery. J. Phys. Chem. C 2017, 121 (18), 9748-9756.

(32) Olson, D. W.; Virta, R. L.; Mahdavi, M.; Sangine, E. S.; Fortier, S. M., Natural Graphite Demand and Supply - Implications for Electric Vehicle Battery Requirements. Geol. S. Am. S. 2016, 520, SPE520-508.

(33) Matthews, P. D.; King, T. C.; Glass, H.; Magusin, P. C. M. M.; Tustin, G. J.; Brown, P. A. C.; Cormack, J. A.; García-Rodríguez, R.; Leskes, M.; Dutton, S. E.; Barker, P. D.; Grosche, F. M.; Alavi, A.; Grey, C. P.; Wright, D. S., Synthesis and Extensive Characterisation of Phosphorus Doped Graphite. RSC Adv. 2016, 6 (67), 62140-62145.

(34) Moder, K. P., Phosphorus(III) Chloride. in e-EROS Encyclopedia of Reagents for Organic Synthesis, 2001.

(35) Bhattacharyya, P.; Gudmunsen, D.; Hope, E. G.; Kemmitt, R. D.; Paige, D. R.; Stuart, A. M., Phosphorus (III) Ligands with Fluorous Ponytails. J. Chem. Soc. Perk. T1 1997, (24), 3609-3612.

(36) Bhattacharyya, P.; Croxtall, B.; Fawcett, J.; Fawcett, J.; Gudmunsen, D.; Hope, E. G.; Kemmitt, R. D.; Paige, D. R.; Russell, D. R.; Stuart, A. M., Phosphorus (III) Ligands in Fluorous Biphase Catalysis. J. Fluorine Chem. 2000, 101 (2), 247-255.

(37) Forbes, M. C.; Roswell, C. A.; Maxson, R. N.; Booth, H. S.; Dolance, A., Phosphorus(III) Chloride. in Inorganic Syntheses, Fernelius, W. C., Ed. John Wiley \& Sons, Inc.: Hoboken, NJ, USA, 1946; Vol. 2. 
(38) Benbrook, C. M., Trends in Glyphosate Herbicide Use in the United States and Globally. Environ. Sci. Eur. 2016, 28 (1), 3.

(39) Kahlenberg, L., Instantaneous Chemical Reactions and the Theory of Electrolytic Dissociation. J. Phys. Chem. 1902, 6 (1), 1-14.

(40) Zhou, P.; Lee, R.; Claye, A.; Fischer, J. E., Layer Disorder in Carbon Anodes. Carbon 1998, 36 (12), 1777-1781.

(41) Li, Z.; Lu, C.; Xia, Z.; Zhou, Y.; Luo, Z., X-Ray Diffraction Patterns of Graphite and Turbostratic Carbon. Carbon 2007, 45 (8), 1686-1695.

(42) Vidano, R. P.; Fischbach, D. B.; Wills, L. J.; Loehr, T. M., Observation of Raman Band Shifting with Excitation Wavelength for Carbons and Graphites. Solid State Commun. 1981, 39 (2), 341-344.

(43) Ferrari, A. C.; Robertson, J., Interpretation of Raman Spectra of Disordered and Amorphous Carbon. Phys. Rev. B 2000, 61 (20), 14095-14107.

(44) Wu, J.; Mao, N.; Xie, L.; Xu, H.; Zhang, J., Identifying the Crystalline Orientation of Black Phosphorus Using Angle-Resolved Polarized Raman Spectroscopy. Angew. Chem. 2015, 127 (8), 23962399.

(45) Andres, C.-G.; Leonardo, V.; Elsa, P.; Joshua, O. I.; Narasimha-Acharya, K. L.; Sofya, I. B.; Dirk, J. G.; Michele, B.; Gary, A. S.; Alvarez, J. V.; Henny, W. Z.; Palacios, J. J.; Herre, S. J. v. d. Z., Isolation and Characterization of Few-Layer Black Phosphorus. 2D Mater. 2014, 1 (2), 025001.

(46) Goldstein, J. I.; Newbury, D. E.; Michael, J. R.; Ritchie, N. W.; Scott, J. H. J.; Joy, D. C., Scanning Electron Microscopy and XRay Microanalysis. Springer: 2017.

(47) Hahn, E. L., Spin Echoes. Phys. Rev. 1950, 80 (4), 580594.

(48) Andrew, E. R.; Bradbury, A.; Eades, R. G., Nuclear Magnetic Resonance Spectra from a Crystal Rotated at High Speed. Nature 1958, 182, 1659.

(49) Lowe, I. J., Free Induction Decays of Rotating Solids. Phys. Rev. Lett. 1959, 2 (7), 285-287.

(50) Ramireddy, T.; Xing, T.; Rahman, M. M.; Chen, Y.; Dutercq, Q.; Gunzelmann, D.; Glushenkov, A. M., PhosphorusCarbon Nanocomposite Anodes for Lithium-Ion and Sodium-Ion Batteries. J. Mater. Chem. A 2015, 3 (10), 5572-5584.

(51) Bytchkov, A.; Fayon, F.; Massiot, D.; Hennet, L.; Price, D. L., ${ }^{31} \mathrm{P}$ Solid-State NMR Studies of the Short-Range Order in Phosphorus-Selenium Glasses. Phys. Chem. Chem. Phys. 2010, 12 (7), 1535-1542.

(52) Watts, J. F.; Wolstenholme, J., Electron Spectroscopy: Some Basic Concepts. in An Introduction to Surface Analysis by XPS and AES, John Wiley \& Sons, Ltd: 2005; pp 1-15.

(53) Chastain, J.; King, R. C.; Moulder, J., Handbook of X-Ray Photoelectron Spectroscopy: a Reference Book of Standard Spectra for Identification and Interpretation of XPS Data. Physical Electronics Division, Perkin-Elmer Corporation Eden Prairie, Minnesota: 1992

(54) Wang, Y.; Zuo, S.; Yang, J.; Yoon, S.-H., Evolution of Phosphorus-Containing Groups on Activated Carbons During Heat Treatment. Langmuir 2017, 33 (12), 3112-3122.

(55) Choi, C. H.; Park, S. H.; Woo, S. I., Binary and Ternary Doping of Nitrogen, Boron, and Phosphorus into Carbon for Enhancing Electrochemical Oxygen Reduction Activity. ACS Nano 2012, 6 (8), 7084-7091.

(56) Li, Z.; Ma, L.; Surta, T. W.; Bommier, C.; Jian, Z.; Xing, Z.; Stickle, W. F.; Dolgos, M.; Amine, K.; Lu, J.; Wu, T.; Ji, X., High Capacity of Hard Carbon Anode in Na-Ion Batteries Unlocked by $\mathrm{PO}_{\mathrm{x}}$ Doping. ACS Energ. Lett. 2016, 1 (2), 395-401.

(57) Li, Z.; Bommier, C.; Chong, Z. S.; Jian, Z.; Surta, T. W.; Wang, X.; Xing, Z.; Neuefeind, J. C.; Stickle, W. F.; Dolgos, M.; Greaney, P. A.; Ji, X., Mechanism of Na-Ion Storage in Hard Carbon Anodes Revealed by Heteroatom Doping. Adv. Energ. Mater. 2017, 7 (18), 1602894

(58) Patel, M. A.; Luo, F.; Khoshi, M. R.; Rabie, E.; Zhang, Q.; Flach, C. R.; Mendelsohn, R.; Garfunkel, E.; Szostak, M.; He, H., PDoped Porous Carbon as Metal Free Catalysts for Selective Aerobic
Oxidation with an Unexpected Mechanism. ACS Nano 2016, 10 (2), 2305-2315.

(59) Qiang, Z.; Xia, Y.; Xia, X.; Vogt, B. D., Generalized Synthesis of a Family of Highly Heteroatom-Doped Ordered Mesoporous Carbons. Chem. Mater. 2017, 29 (23), 10178-10186.

(60) Yang, D.-S.; Bhattacharjya, D.; Inamdar, S.; Park, J.; Yu, J.-S., Phosphorus-Doped Ordered Mesoporous Carbons with Different Lengths as Efficient Metal-Free Electrocatalysts for Oxygen Reduction Reaction in Alkaline Media. J. Am. Chem. Soc. 2012, 134 (39), 16127-16130.

(61) Zhang, M.; Dai, L., Carbon Nanomaterials as Metal-Free Catalysts in Next Generation Fuel Cells. Nano Energy 2012, 1 (4), 514-517.

(62) Choi, C. H.; Park, S. H.; Woo, S. I., Phosphorus-Nitrogen Dual Doped Carbon as an Effective Catalyst for Oxygen Reduction Reaction in Acidic Media: Effects of the Amount of P-Doping on the Physical and Electrochemical Properties of Carbon. J. Mater. Chem. 2012, 22 (24), 12107-12115.

(63) Li, R.; Wei, Z.; Gou, X.; Xu, W., Phosphorus-Doped Graphene Nanosheets as Efficient Metal-Free Oxygen Reduction Electrocatalysts. RSC Adv. 2013, 3 (25), 9978-9984.

(64) Yang, N.; Zheng, X.; Li, L.; Li, J.; Wei, Z., Influence of Phosphorus Configuration on Electronic Structure and Oxygen Reduction Reactions of Phosphorus-Doped Graphene. J. Phys. Chem. C 2017, 121 (35), 19321-19328.

(65) Li, F.; Shu, H.; Liu, X.; Shi, Z.; Liang, P.; Chen, X., Electrocatalytic Activity and Design Principles of Heteroatom-Doped Graphene Catalysts for Oxygen-Reduction Reaction. J. Phys. Chem. C 2017, 121 (27), 14434-14442.

(66) Liu, Z. W.; Peng, F.; Wang, H. J.; Yu, H.; Zheng, W. X.; Yang, J., Phosphorus-Doped Graphite Layers with High Electrocatalytic Activity for the $\mathrm{O}_{2}$ Reduction in an Alkaline Medium. Angew. Chem. Int. Ed. 2011, 50 (14), 3257-3261.

(67) Hu, C.; Dai, L., Carbon-Based Metal-Free Catalysts for Electrocatalysis Beyond the ORR. Angew. Chem. Int. Ed. 2016, 55 (39), 11736-11758

(68) Liu, X.; Dai, L., Carbon-Based Metal-Free Catalysts. Nat. Rev. Mater. 2016, 1, 16064

(69) Kühl, O., Phosphorus-31 NMR Spectroscopy: a Concise Introduction for the Synthetic Organic and Organometallic Chemist. Springer: Berlin, 2008

(70) Mal, P.; Breiner, B.; Rissanen, K.; Nitschke, J. R., White Phosphorus Is Air-Stable within a Self-Assembled Tetrahedral Capsule. Science 2009, 324 (5935), 1697-1699.

(71) Nazri, G., Preparation, Structure and Ionic Conductivity of Lithium Phosphide. Solid State Ionics 1989, 34 (1-2), 97-102.

(72) Li, W.; Yang, Y.; Zhang, G.; Zhang, Y.-W., Ultrafast and Directional Diffusion of Lithium in Phosphorene for HighPerformance Lithium-Ion Battery. Nano Lett. 2015, 15 (3), 16911697.

(73) Sun, J.; Lee, H.-W.; Pasta, M.; Yuan, H.; Zheng, G.; Sun, Y.; Li, Y.; Cui, Y., A Phosphorene-Graphene Hybrid Material as a High-Capacity Anode for Sodium-Ion Batteries. Nat. Nanotechnol. 2015, 10, 980-985.

(74) Ueda, A.; Nagao, M.; Inoue, A.; Hayashi, A.; Seino, Y.; Ota, T.; Tatsumisago, M., Electrochemical Performance of All-SolidState Lithium Batteries with $\mathrm{Sn}_{4} \mathrm{P}_{3}$ Negative Electrode. J. Power Sources 2013, 244, 597-600.

(75) Sun, J.; Zheng, G.; Lee, H. W.; Liu, N.; Wang, H.; Yao, H.; Yang, W.; Cui, Y., Formation of Stable Phosphorus-Carbon Bond for Enhanced Performance in Black Phosphorus Nanoparticle-Graphite Composite Battery Anodes. Nano Lett. 2014, 14 (8), 4573-4580.

(76) Ruan, J.; Yuan, T.; Pang, Y.; Xu, X.; Yang, J.; Hu, W.; Zhong, C.; Ma, Z.-F.; Bi, X.; Zheng, S., Red Phosphorus-Embedded Cross-Link-Structural Carbon Films as Flexible Anodes for Highly Reversible Li-Ion Storage. ACS Appl. Mater. Inter. 2017, 9 (41), 36261-36268

(77) Marino, C.; Boulet, L.; Gaveau, P.; Fraisse, B.; Monconduit, L., Nanoconfined Phosphorus in Mesoporous Carbon as 
an Electrode for Li-Ion Batteries: Performance and Mechanism. $J$. Mater. Chem. 2012, 22 (42), 22713-22720.

(78) Yue, Z.; Gupta, T.; Wang, F.; Li, C.; Kumar, R.; Yang, Z.; Koratkar, N., Utilizing a Graphene Matrix to Overcome the Intrinsic
Limitations of Red Phosphorus as an Anode Material in Lithium-Ion Batteries. Carbon 2018, 127, 588-595.
2

3

4

5

6

7

8

9

10

11

12

13

14

15

16

17

18

19

20

21

22

23

24

25

26

27

28

29

30

31

32

33

34

35

36

37

38

39

40

41

42

43

44

45

46

47

48

49

50

51

52

53

54

55

56

57

58

59

60 
TOC Graphic

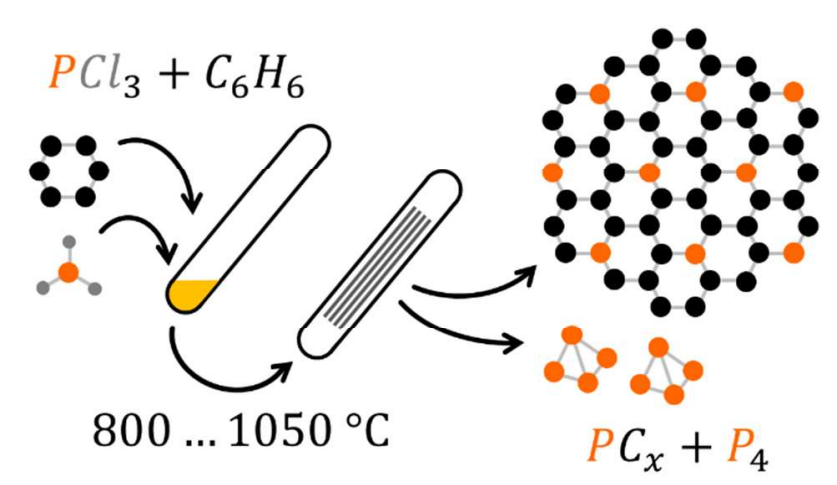



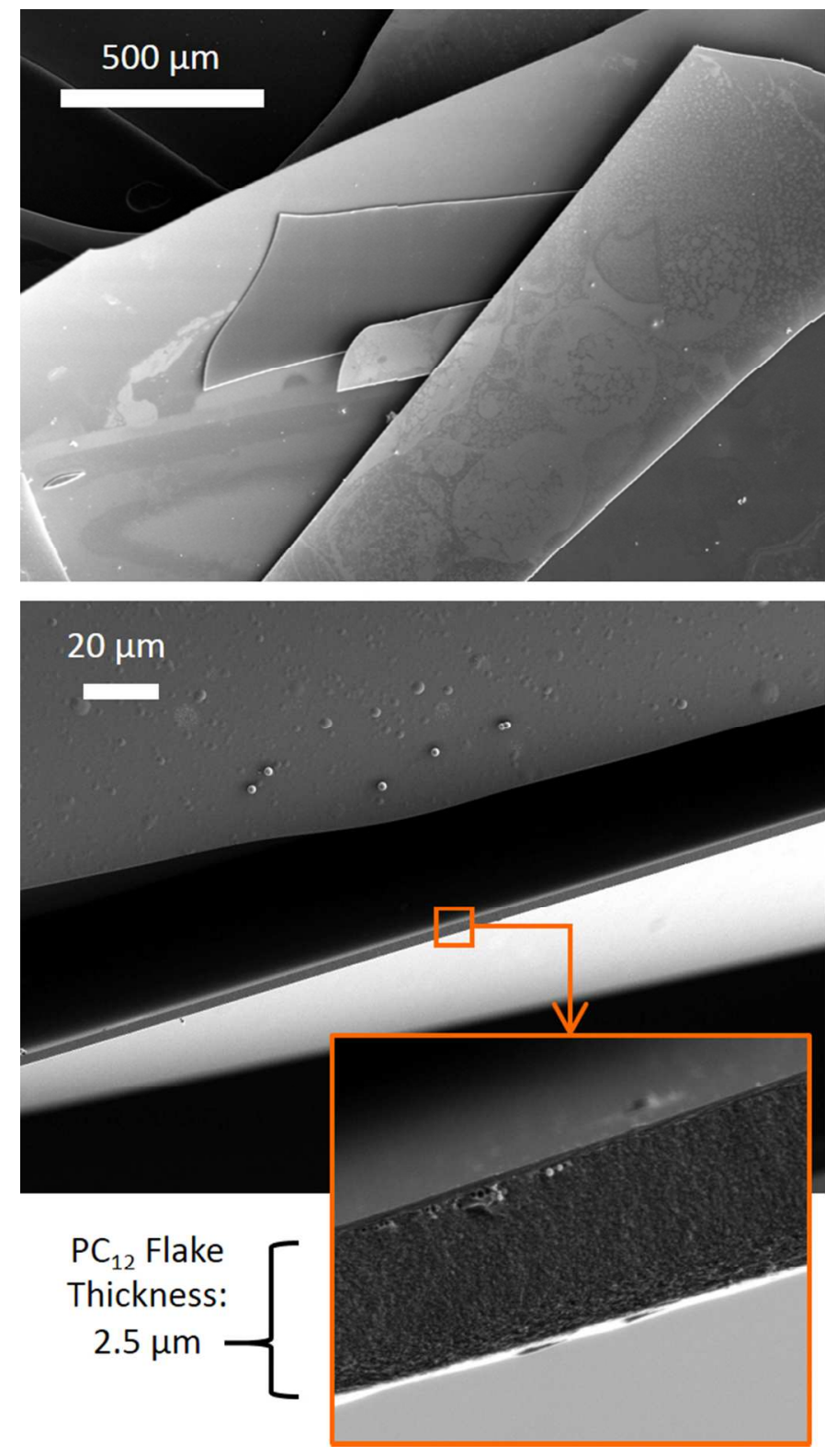

Fig 1. SEM micrographs of typical bulk PCx materials obtained by direct synthesis from $\mathrm{PCl} 3$ and benzene. The dark metallic flakes vary in thickness between 2-4 $\mu \mathrm{m}$.

$$
142 \times 254 \mathrm{~mm}(120 \times 120 \text { DPI })
$$




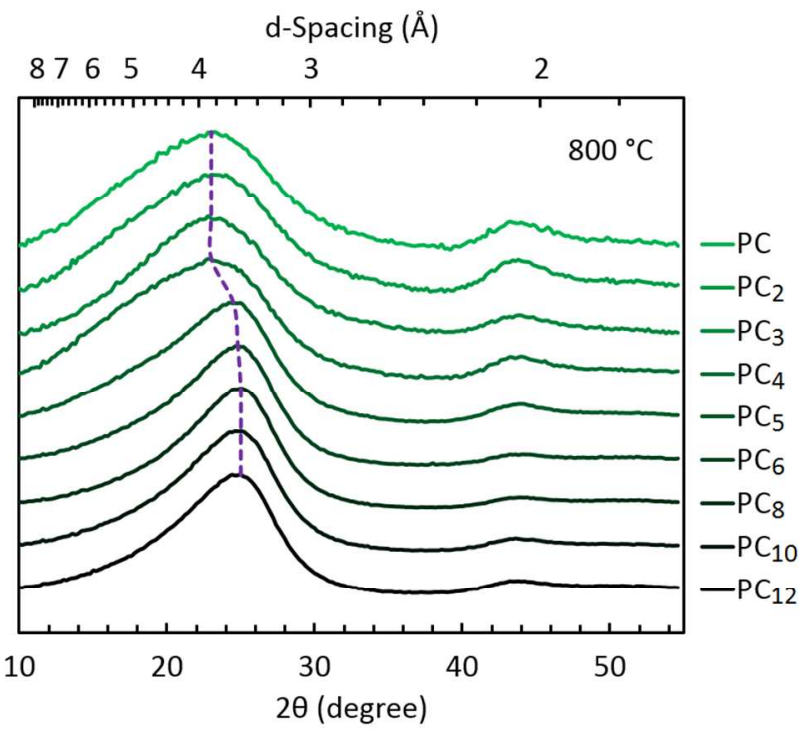

\section{$\begin{array}{llllll}87 & 6 & 5 & 4 & 3 & 2\end{array}$}

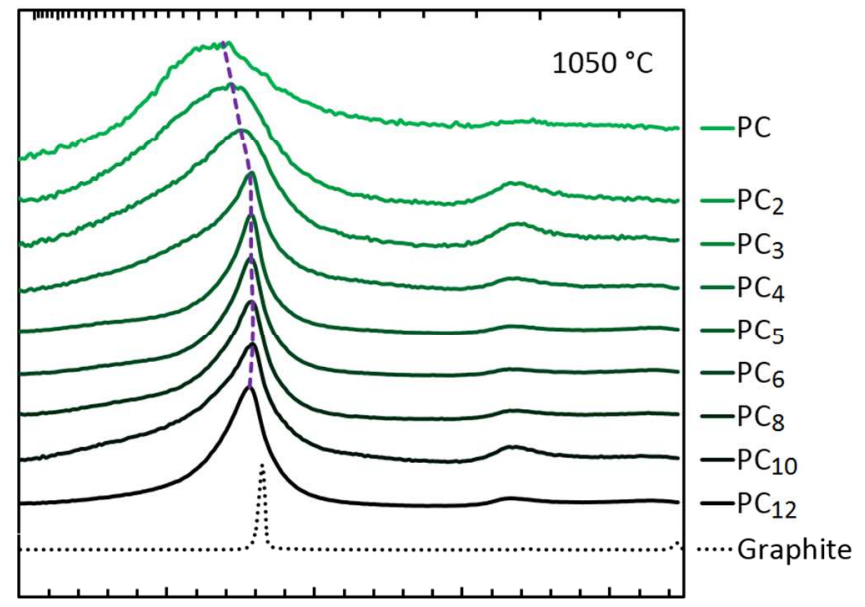

10

20

$\begin{array}{ll}30 & 40 \\ 2 \theta \text { (degree) }\end{array}$

Fig 2. XRD patterns of (top) PCx synthesized at $800{ }^{\circ} \mathrm{C}$ for $1 \mathrm{~h}$, varying nominal composition between $1 \leq \mathrm{x} \leq 12$, and (bottom) PCx synthesized at $1050^{\circ} \mathrm{C}$ for $1 \mathrm{~h}$, varying nominal composition between $1 \leq \mathrm{x} \leq 12$. Crystalline graphite (dotted line) is also shown for comparison.

$196 \times 337 \mathrm{~mm}(120 \times 120 \mathrm{DPI})$ 


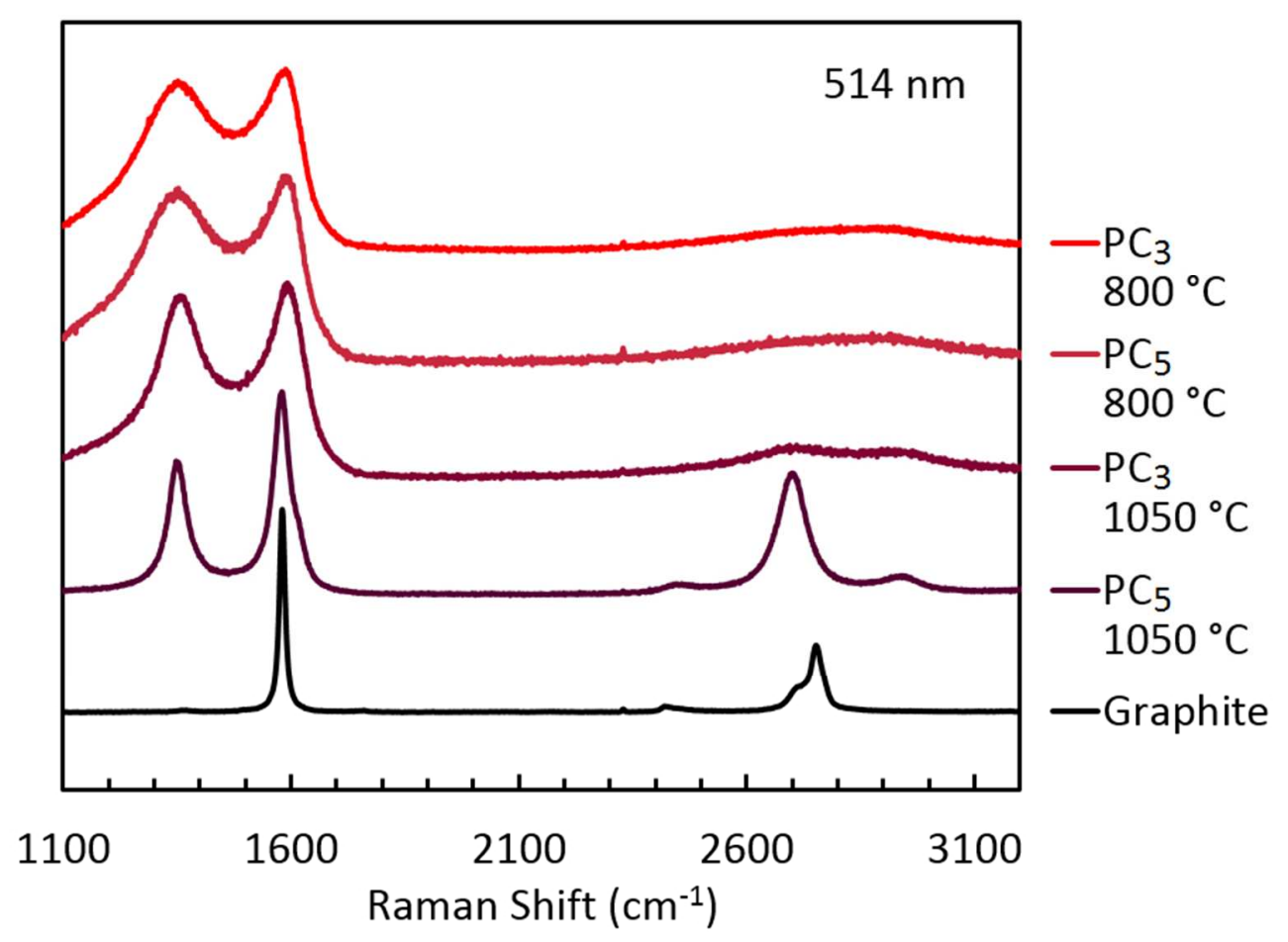

Fig. 3. Raman spectra of PC3 and PC5 synthesized at $800^{\circ} \mathrm{C}$ and $1050^{\circ} \mathrm{C}$. Crystalline graphite (black) is shown for comparison.

$193 \times 140 \mathrm{~mm}(120 \times 120$ DPI $)$ 


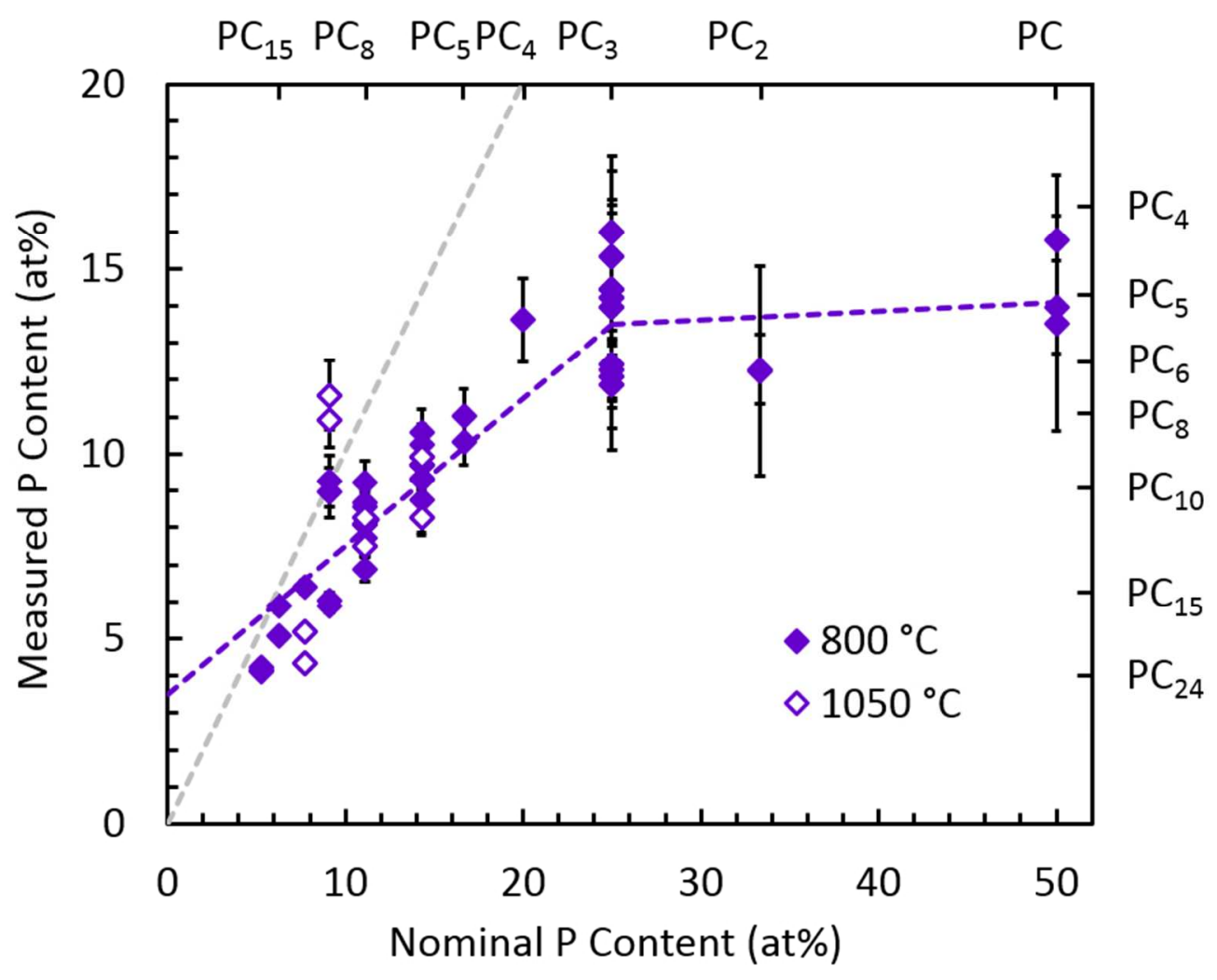

Elemental composition of PCx samples synthesized at $800^{\circ} \mathrm{C}$ (filled symbols) and $1050{ }^{\circ} \mathrm{C}$ (empty symbols) as determined by EDX spectroscopy. The data are fitted (dashed purple line) in two regions as a visual guide, and compared to an ideal 1:1 dependence (dashed gray line).

$188 \times 154 \mathrm{~mm}(120 \times 120 \mathrm{DPI})$ 


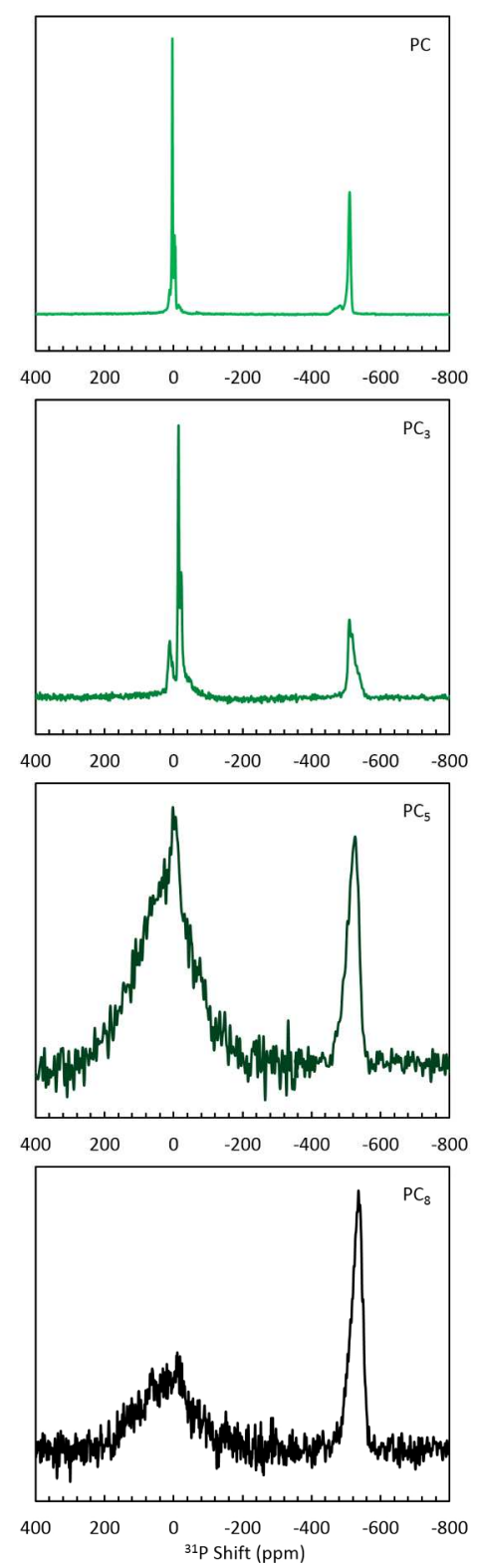

Fig. 5. 31P MAS NMR spectra of PC, PC3, PC5, and PC8 synthesized at $1050{ }^{\circ} \mathrm{C}$, showing three distinct phosphorus environments within the bulk of the material: P4 $(-530 \mathrm{ppm}), \mathrm{PC}$ species (200 to $-100 \mathrm{ppm})$, and phosphate ( $\sim 0 \mathrm{ppm})$.

$157 \times 538 \mathrm{~mm}(120 \times 120 \mathrm{DPI})$ 


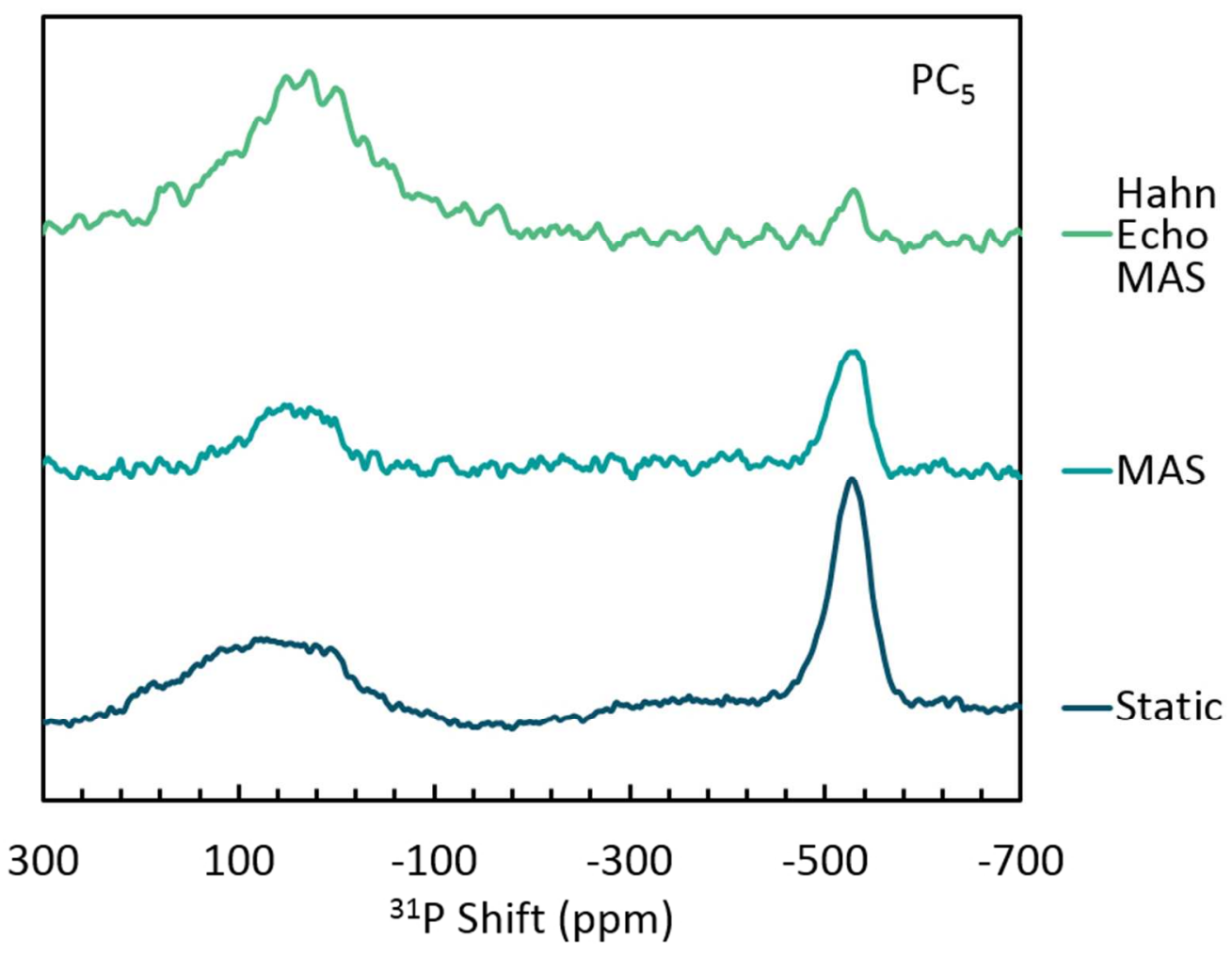

Fig. 6. 31P NMR spectra of PC5 synthesized at $1050^{\circ} \mathrm{C}$ under different experimental conditions: a Hahn echo experiment under $20 \mathrm{kHz}$ MAS (light green), a single $30^{\circ}$ pulse (zg30) under $20 \mathrm{kHz}$ MAS (light blue), and a single $30^{\circ}$ pulse (zg30) in static mode (dark blue).

$180 \times 140 \mathrm{~mm}(120 \times 120 \mathrm{DPI})$ 

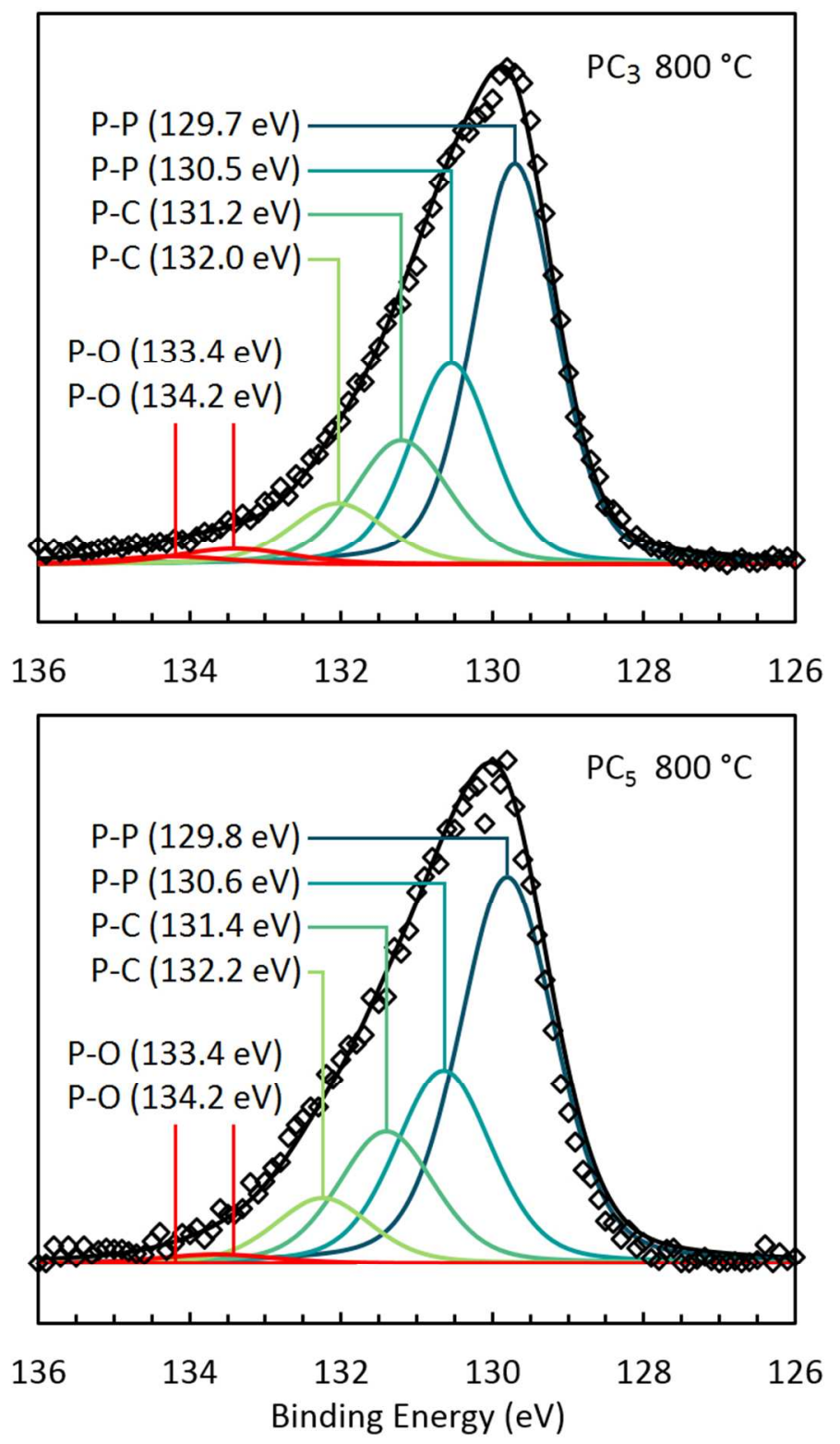

Fig. 7. XPS spectra of PC3 and PC5 synthesized at $800{ }^{\circ} \mathrm{C}$ in the $P 2 p$ region (black symbols), showing contributions primarily from P-P (blue lines) and P-C (green lines) bonding environments in the material bulk (i.e., after 20 min of argon ion sputtering).

$157 \times 273 \mathrm{~mm}(120 \times 120 \mathrm{DPI})$ 